Running Head: BUILDING TRUST TO RELIEVE GRADUATE RESEARCH ANXIETY

Building Trust to Relieve Graduate Student Research Anxiety

Stacy N. Brinkman and Arianne A. Hartsell-Gundy

Miami University, Oxford, Ohio

Published version appears in Public Services Quarterly, 8:26-39, 2012 


\begin{abstract}
This paper outlines the case studies of two librarians who work closely with graduate students in fine arts programs. Realizing that graduate students can often experience a unique form of research anxiety, both librarians collaborated with faculty to embed themselves into the research methods courses of their programs. Both librarians found that the chance to work one-on-one with graduate students resulted in a reduction of their anxiety, an increase in information literacy skills, and a strengthened partnership between the librarians and the departments.
\end{abstract}




\section{Building Trust to Relieve Graduate Student Research Anxiety}

Graduate students are a very diverse population: a single cohort can span a wide range of ages, ethnicities, backgrounds, educations, and life experiences. An increasing number of graduate students are from other countries, have families, or are returning to higher education after a long break. They have different levels of comfort with technology, libraries, research, and writing, as well as very different levels of ability to find, access, evaluate, and ethically use information. Most universities require graduate students to conduct independent and original research, and while many graduate programs offer "Research Methods" courses to help prepare them for this work, such courses do not always address issues of information literacy or anxieties that may hinder the success of a student's research project.

Two librarians at Miami University have begun collaborating with faculty to address the information literacy needs of graduate students who are taking their research methods courses. The two programs we work with are interdisciplinary pre-professional programs (Architecture and Theatre). It's not uncommon for the students to be returning to graduate school after working in the field for several years. Based on the unique needs of the graduate students in our programs, we decided to use an embedded approach (instruction throughout a semester and oneon-one relationships) to help build relationships with graduate students, who often suffer from a unique form of research anxiety.

\section{Literature Review}

While some people might argue that graduate students do not need in-depth library instruction because they already have strong research skills, studies of graduate student information literacy suggest that this not the case. A 2009 study of psychology graduate students by Marni Harrington found, among other results, that only $80 \%$ of graduate students felt it was 
important to exhaustively search the literature before beginning their research projects, which can be a major problem: "failing to correctly search the literature could result in spending a substantial amount of time planning and conducting research that has already been published" (182). An information literacy audit done in Australia in 2003 found that over $50 \%$ of graduate students overestimated their information searching skills (Perrett, p. 1). A 2007 survey of academic dishonesty cases in graduate school revealed that although most faculty and administrators think graduate students start their programs with an understanding of how to cite properly and how to avoid plagiarism, this assumption is not really true (Caravello, p. 2).

Studies also indicate that graduate students have information needs, experiences, and motivations that are distinct from those of undergraduates and faculty. There has been extensive research on the information literacy needs of undergraduates, including the 2010 Project Information Literacy Survey. This survey reported that undergraduates doing course-related research were most interested in passing the course (99\%), finishing the assignment (97\%), and getting a good grade (97\%). Conversely, studies have shown that graduate students doing course-related research are often most interested in how the research they are doing will relate to their own scholarly interests. Bonnie Cummings-Vickaryous et al. (2010) found that "development of student research skills is enhanced through student engagement in a real-world research project. This authentic learning experience, although stressful and overwhelming within the timelines of the course schedule, was instrumental in assisting the students to believe they could move forward with greater independence as researchers" (p. 1). At the same time, it is important to remember that while their motivations for engaging in research may be more similar to faculty than undergraduates, graduate students are still developing as scholars. A study conducted by Andy Barrett in 2005 suggests that the research skills and habits that graduate 
students develop during these "extremely formative years in their academic careers" will influence the kind of research they do in for the rest of their lives (p. 330). In other words, we cannot see graduate students as just slightly more advanced undergraduates, but we also can't treat them as being exactly like faculty.

There have been a number of approaches taken in developing information literacy among graduate students. In her 2009 article, Barbara Blummer provides a thorough examination of many of these approaches over the past 50 years. These approaches have included tactics such as library tours, workshops, course-integrated instruction, mandatory training sessions, guidebooks, and one-on-one consultations. Many of the chapters in the edited volume Libraries and Graduate Students: Building Connections (Siegel, 2009) further examine the information and research needs of graduate students and detail what individual libraries are doing to help graduate students. What these studies by Blummer and Siegel show is that information literacy instruction to graduate students has come a long way, particularly in the last two decades. Increasingly, information literacy standards are being integrated into graduate curriculums and into graduate courses, often through partnerships between librarians and faculty members, and often utilizing new technologies such as course management software, videoconferencing, or web tutorials.

Although many of these approaches to information literacy have been successful, they do not always address the affective needs of graduate students. One of the most important differences between undergraduate and graduate students is that most graduate programs require students to conduct original and independent research, most often in the form of a thesis. While most graduate students were successful as undergraduates, many have never conducted a largescale independent investigation before, often resulting in heightened anxiety about their research 
projects. A series of studies conducted in 1997 and 1998 demonstrated that library anxiety, defined as "an uncomfortable feeling or emotional disposition, experienced in a library setting, which has cognitive, affective, physiological, and behavioral ramifications" (Onwuegmuzie et al., 2004, 25), can have debilitating effects on graduate students, particularly in their ability to write research proposals (Onwuegbuzie \& Jiao, 1998, 218). Research by Kuhlthau (1998) also suggests that negative emotions associated with library anxiety interfere with the overall search process and the development of information literacy.

In a 2002 article, Green and Bowser describe how a faculty-librarian collaboration in four courses helped to alleviate thesis anxiety for distance graduate students in education at Shenendoah University. While the quantitative results of the study were inconclusive, mainly due to the small sample size and non-validated survey instrument, qualitative data suggests that the graduate students benefited greatly from the program. While Green and Bowser's article does not describe their program in great detail, the concept of embedding a librarian into the entire thesis process is noteworthy for several reasons. First, it is not just integrated with a single course, and therefore ties in with the graduate student's long-term research interests and goals. Furthermore, it allows graduate students to associate a physical person (the librarian) with the research process, as opposed to integrating principles of information literacy into the process without assigning a specific person.

The significance of relationship-building with graduate students in their thesis work is not trivial. As early as 1987, Kazlauskas suggested that the most effective approach to promote information literacy in graduate students was through one-on-one interviews (p. 10). In terms of alleviating research anxiety, it is also important to realize that the librarians themselves can be a source of anxiety for graduate students: research by Jiao and Onwuegbuzie (1997) suggests that 
especially for students who are male, who are non-native English speakers, who work full-time, or who have a heavy course load, the perception that librarians are "too busy to help" can lead to increased library anxiety (p. 217). Therefore, it is important to cultivate relationships with graduate students early in their careers, so that librarians are seen as allies in the process of transitioning from being students to becoming scholars. Furthermore, establishing the librarian as an ally can potentially lead to future collaborations should these graduate students go on to become faculty members.

Our paper describes two approaches for establishing such relationships that have been effective at Miami University, a mid-size, public Midwestern university. Similar to the approach described by Green and Bowser (2002), librarians were embedded into a cohort of graduate students, beginning with a research methods class, but continuing throughout the entire thesis process. Although the term "embedded librarian" has taken on a variety of meanings, a comprehensive report for the Special Libraries Association in 2009 describes it best: at their core, embedded models are "customer [or student] centric not library centric," they are "located in their workplace," and they focus on building relationships, often in small groups (Shumaker and Talley, p. 9). Our two case studies were developed independently, but they both focus on personal, relationship-centered research support, rather than library-centered instruction. Both librarians emphasized building trust with the graduate students, an important element when trying to overcome the research anxiety so common to this population.

\section{Case Study 1: M.A. in Theatre}

Introduction of Program and Course

Graduate students in the Theatre program at Miami University earn a Master of Arts rather than a Master of Fine Arts (M.F.A). Most students finish the program in two years. After 
earning this degree, some of the students move into a doctorate program or an M.F.A at another institution. Others use the experience to launch their directing or acting careers. Graduate students in this program take a required research methods course during their first semester. The course focuses on both research methodologies (such as feminist theory or historiography) and methods particular to that discipline, and usually there are about 5-10 students in this class. The research paper they write as the culmination of this class is presented at a graduate student colloquium. Many of the students also go on to either present their paper at a national conference or develop it into their thesis. This course is designed to prepare them to start writing their master's thesis the next year, which made it an ideal place for me (the Theatre liaison) to begin forming relationships with the graduate students.

Faculty-Librarian Collaboration

The professor of the course (who also served as the director of the department's graduate studies program) was concerned about this class because many of the students in this Theatre program come in as practitioners rather than researchers. They may be very good actors or set designers, but they may not have written a research paper for many years. The professor wanted his students to become a part of the academic conversation and to understand the research of the discipline, so that they could be successful in the next steps of the program.

The professor approached me shortly after I started working at this institution to discuss his concerns. The first semester he approached me I did a traditional library session in their course. Though the students appreciated the resources I shared with them, the professor told me afterwards that he felt like the students still struggled with the research process. After initial discussions, we had the chance to work together on a Faculty Learning Community for Research Literacy. This experience helped us figure out some strategies for incorporating information 
literacy into the class. In particular we became interested in the concept of scaffolding that was discussed in the community. We were especially influenced by Bordonaro's article "Scaffolding and Reflection in Course-Integrated Library Instruction.” In that article Bordonaro uses a definition of scaffolding from the ERIC Thesaurus: "[...] the technique builds knowledge/skills until learners can stand on their own, similar to scaffolding on a building" to describe the process that was used to integrate library instruction into a course (p. 397). We felt the idea of scaffolding would work well with our goal for students to understand research as a process, even though it would require more involvement of the librarian.

As a result of our work in this community, we agreed that we wanted the students to have more than just a one-shot library session that reviewed helpful tools. We agreed that I should be embedded into the course in order to support the graduate students as they began to explore not just the nuts and bolts of research, but try to understand the research process and their role as scholars.

We also worked together to redesign the research paper assignment. He agreed to add an annotated bibliography assignment that was turned in before the research paper. This assignment required students to begin their research earlier in the semester and to think carefully about the resources they chose to use. In the annotated bibliography students not only listed articles that they intended to cite in their research papers, but they were also required to cite resources related to their research paradigm (such as psychoanalysis or post-colonialism) and survey the research landscape of their topic for the last five years.

\section{Librarian's Involvement in the Course}

The professor and I agreed that I should be involved throughout the course, so I taught three individual sessions instead of just one. This course met once a week for three hours, so I 
spent a total of nine hours inside the classroom during the semester. Two of those sessions included showing print and electronic resources and talking about different research strategies. I included not just Theatre resources but also tools that are helpful for the entire research process. We spent time talking about the nature of research, how to brainstorm, understanding how Theatre research is unique, etc. We discussed how to find primary sources using online databases, how to do research in archives, and went on a tour of our Special Collections. During all of these in-class sessions the professor and I modeled different ways to do research to help the students understand how the process works.

The third session was a more informal session where the librarian, the professor, and the students talked about their experiences with research. The students also had a chance during that session to talk about their individual research projects. Each student had about five minutes to describe the project and mention any research problems. For example, one student wanted to do his research project on a kind of Thai theatre that involves male actors dressing up as women. This particular student was both an international student and a returning student. He was less familiar with research than some of the other students. Though he was interested in gender issues, the proposal he shared with the class focused mainly on giving a history of that type of theatre. It quickly became clear to the professor and to me that the student needed to have a more focused research argument and that he needed to ground his argument in queer theory in order to avoid his paper becoming just a historical summary. After we began to make some suggestions, his classmates began to bring in suggestions as well. We had a lively discussion about not just the importance of theory for Theatre research, but also the nature of theory. In particular the professor suggested the student compare Western queer theory with queer theory in Thailand. 
Each student was also required to meet one-on-one with me at least once. During this one-on-one meeting students would talk about their difficulties with research, and I could focus on helping them find solutions specific to their research queries rather than trying to provide general advice to the entire class. The required meeting took place after students had written the annotated bibliographies, so I was able to use the bibliographies as a way to gauge where they were in the research process and make the meeting more tailored to their needs. These meetings were often very valuable because so many students were in different places in their information literacy skills and their ability to do research. In some cases students would ask questions that they had not wanted to ask during class settings.

In addition to the in-person meetings, I had a virtual presence. I created a library resources page that was included on the Blackboard course site, along with links to the appropriate library subject guides. I made a point to monitor the Blackboard discussion boards at least once a day, so that I could keep track of what the students were discussing and offer advice. I also gave the students my IM chat name, so they could reach me if they had questions while they were doing research. In most cases the students preferred to e-mail me questions rather than chat with me online, but I felt it was important to give them my IM chat name because it made it clear that I was willing to be contacted in multiple ways. The in-person meetings and virtual presence helped to make me a part of the course throughout the semester.

\section{Value of the Experience}

The professor discovered that the bibliographies in the final research paper were stronger than in the previous semester. We believe they were better partially because the professor and I looked over these bibliographies and provided feedback on the students' work in the middle of the semester. In some cases we were able to catch major problems students were having with the 
research. In all cases we were able to make suggestions on where to go next. Students were able to use the annotated bibliographies and our feedback to guide their writing, which we saw as evidence that our efforts to scaffold the research process were successful. Other evidence of the value of the librarians' involvement included lively discussions during the classes that the librarian attended and very positive formal evaluations from the students at the end of the third in-class session.

The best result of being embedded has been the ongoing relationships I have formed with students in this program. Most students met with me more than the one required time mentioned previously. I was invited to attend the end of the semester colloquium where the students read their papers, which was a chance for me to see how the research projects had improved from when I first met with the students. Students I worked with the first semester I was embedded in the course are now working on, or have recently finished, their master's thesis projects. Most of those students have contacted me to help them with research for other classes, conference papers, and the thesis itself. Their questions often go beyond just how to use a database or track down a journal article. For example I've had students talk to me about how to form their research question, ask me about the Institutional Review Board (IRB) process, and ask for advice on how to conduct a thorough literature review. In some cases I have had students who just wanted to meet with me for a pep talk to help them push through the difficulties of graduate school. The chance to see these students grow as they go through the program has been very valuable for me. I think these examples really illustrate how I have been able to build trust with these graduate students and as a result help ease their research anxiety. They know they have another ally as they move through their graduate program.

\section{Future Steps}


The professor and I have both agreed that we want to continue this embedded approach in future semesters. I look forward to making new relationships with new graduate students every semester and plan to continue to make changes to what I cover (and how I cover it) as I learn more about what these students need to learn. Recently I have discovered that the graduate students in the program sometimes need more help with understanding research methods that are less traditional in Theatre research. For instance they sometimes need guidance on how to go through the IRB approval process, and how to conduct interviews and surveys, particularly those doing audience response research.

I appreciate that my relationship with the Theatre department has strengthened as a result of being embedded in this course. In fact an updated version of this course was recently submitted to the university curriculum committee for approval. This updated version included language about having an embedded librarian as a feature of the course and language about acquiring information literacy was included in the student learning outcomes.

\section{Case Study 2: M.Arch in Architecture}

\section{Program Description}

The M. Arch program at Miami University is a nationally accredited, pre-professional program that qualifies its graduates towards professional architectural licensure. Students are admitted into a 2-year program or a 3-year program, depending on their level of undergraduate preparation. The final three semesters of study center around a thesis project that involves both a written and a design portion. The size of a thesis cohort varies by year, with most classes ranging from 12-16 students. 
In the spring preceding their final year of study in the program, students take a course called "Design and Research Methods in Architecture." Students enter this course with varying degrees of clarity about their thesis: some have relatively focused research topics, while others have a difficult time identifying specific areas of interest. By the time students finish this course, they should have a partial draft of their written thesis completed with an outline of their plans to continue their thesis work over the summer. When they return in the fall for their final year, students formally present their written thesis early in the first semester, and then continue to complete the design portion of their thesis based on their research by the following spring.

"Design and Research Methods" is therefore the first course in a 3-semester sequence of thesis-centered work. Central concepts in the course include defining a viable thesis topic, identifying valid sources and methodologies for the thesis inquiry, contextualizing the thesis inquiry through a narrative literature review, and presenting the thesis inquiry in a concise written form for an academic audience. Furthermore, students should develop a better understanding of the overall process of research and writing, and its connection with design. As part of the thesis sequence, students are required to submit a version of their thesis as a conference-ready paper in September of their final year to the Association for Collegiate Schools of Architecture (ACSA) Annual Meeting, a peer-reviewed, competitive national conference. Partnership With the Library

While the librarian is not listed as a formal co-instructor in the course (which often requires negotiations of credit-hour compensation), the librarian occupies a central teaching role in the class. I attend every class, co-lead general discussions and assignments, and am listed as a co-instructor on the course Blackboard site, allowing me to post and edit documents. In addition, I read and provide feedback on drafts of student papers, primarily with the role of an "outside 
reader," encouraging students to avoid using jargon or otherwise learn to express their ideas more clearly to non-architects (something they will need to learn to do when working with clients). The classes themselves are held in the library, further emphasizing the central role of the library in the course.

The partnership of this course with the library has been recognized at the departmental level, thereby opening doors for increased collaboration. In 2008, I worked with two faculty members in the department to receive an internal grant to implement more Writing-Across-theCurriculum principles into the course. This provided an additional opportunity to integrate information literacy and writing throughout the course: rather than teaching information literacy concepts in isolation as "workshops" (however problem-based they may be), the goal was to embed information literacy within larger writing assignments of varying degrees of formality. In the overall course revision, we sought to address three interconnected challenges: the challenge of writing (connecting writing to the design process); the challenge of methodology (enabling students to explore and understand the best methodology to address their research question), and the challenge of integrating information literacy throughout the course. While we addressed the challenges individually, we made efforts to ensure that the solutions addressed all three areas of concern together, as we believe the process of research, writing, and design is iterative and integrated, rather than discrete or compartmentalized.

\section{Addressing Anxieties}

One particular challenge for many architecture students is that they are not comfortable with writing. Some students come from undergraduate programs that did not have a strong liberal arts focus, and did not require much research or writing. Others are returning to school after working in the field for many years, but in roles where writing was not emphasized. 
Another major challenge with architectural theses is that, as an interdisciplinary field, architects pursue many different methodologies and forms of inquiry. Some may pose a question that requires historical analysis, while others may pose a question that requires social scientific research such as collecting interviews and conducting a grounded-theory analysis. Still others may take a more artistic approach of sketching and modeling based on a philosophical idea. Most students come into the program only having experience with interpretive or historical approaches to research, largely involving the synthesis or analysis of secondary sources. When presented with the option of other methods such as grounded theory, simulation, correlational, or experimental research, many students experience additional anxiety.

While the class as a whole addresses some of these anxieties through specific assignments and activities, the librarian, in an embedded capacity, also plays an important role in helping students overcome anxiety. I meet with them individually and in small groups to talk about their interests and ideas, and because I attend class sessions, students become familiar with me as a member of and advisor of the course. I also learn through discussions and through reading their assignments what resources the students are finding and investigating. I encourage students to read and evaluate resources with an eye not only for content and authority, but also for methodology. Students are challenged to think about what the underlying research question is in any given paper, and then to evaluate whether the chosen methodology answers the question. Students are also encouraged to think of whether another methodology could answer the same question, and also whether methodological differences would lead to different conclusions.

We also address writing anxiety as a class. At the most basic level, we incorporate more formative "sketch" (or "free") writing exercises into the course, most often in the form of 
journaling. However, we also encourage students to begin to think of themselves as emerging scholars, and to understand that through writing, they are joining the voices of other researchers and professionals in the field. In one particular assignment, students view Milos Forman's 1999 biopic of Andy Kaufman, Man on the Moon, and are asked to consider questions of audience and voice. While the assignment seems unrelated to architecture or research at first, it serves as a touchstone throughout the course: we return to the questions raised in the film-Who is your audience? What voice are you using? - to frame discussions of how to evaluate information, whether one should quote, paraphrase, or summarize, and how a discipline or field can have a particular type of voice. These examples of assignments in the course were developed through dialogue between faculty and librarian, with the interest of helping students understand information literacy concepts while also helping students overcome writing and research anxiety. Librarian as Ally

It is significant that as a librarian, I do not assign grades to any student. In many ways, this enables me to take a role of an ally and supporter rather than an evaluator, even though I provide feedback on papers, presentations, and other work for the course. Within the first weeks of the course, the students know me by name, and continue to schedule appointments with me throughout the next three semesters. I meet with them in small group and in required one-on-one sessions during and outside of class time to focus on search strategies. In class, I help facilitate peer review sessions and lead discussions and workshops on skills such as concept mapping, building annotated bibliographies, citing, and writing for specific audiences. Being in class with them allows me to continually see how their inquiries and projects change over time. Even after the course ends, students continue to talk to me about developing their papers for conferences and presentations, sometimes as an outside reader, and sometimes with questions about research, 
citation, or the IRB process. In my experience, students often need simple encouragement, as they experience uncertainty during multiple stages of the thesis process. Students invite me to their design critiques and presentations, often seeing me as a person who can lend "moral support" in addition to research help. These actions suggest that students regard the librarian as having a significant role as an ally in their research process.

\section{Discussion}

Though there are differences in the way the librarians in the case studies structure their involvement in these classes, both librarians saw many similarities in the two groups of students, particularly in terms of the anxiety they felt. Our students, often coming from diverse backgrounds, struggled with the unique nature of these graduate programs.

Being in the fine arts, both these programs are a blend of professional practice and theory. For instance in the Theatre graduate program, most of the students are furthering their preparation to become directors or actors while also learning about how to research theatre history. Some students (many with bachelor's degrees in English or History) feel very comfortable with more formal research. Other students who have been working in the field as directors and actors for several years struggle with concepts and skills that may seem basic, like writing a thesis statement and finding books in the library. These students are especially prone to anxiety because they know they are behind some of their classmates in terms of these skills. Other students have a hard time balancing the time needed to practice their craft with the time to do graduate level research.

The interdisciplinary nature of these programs was also an issue that students found challenging. Research methods courses provide a natural opportunity for librarians to integrate information literacy into the graduate curriculum. In many fields, a research methods courses are 
relatively structured: students in social sciences learn qualitative and quantitative methodologies, students in natural or life sciences continue to refine lab and field research methods, and students in literature or history may take theory or historiography courses. These courses are largely designed to help graduate students better understand the dominant forms of scholarship in their disciplines, and to prepare them to produce their own research proposal. However, there are some disciplines that are by nature interdisciplinary, without clearly defined dominant methodologies. While interdisciplinarity offers the benefits of allowing students to pursue a project that has much more flexibility, this open-endedness can also lead to increased anxiety and uncertainty about what is actually a viable project. In the case of the Architecture students, many students feel pressured not only to develop a viable research question, but also to determine which methodology and tactics they should use to answer their question.

The two case studies presented demonstrate that a librarian can help diminish some of this research anxiety through extended involvement with a graduate student's research process. However, it is important to consider that building such relationships take time, and should be considered long-term investments. The support of one's department within the library is essential, and it is important for librarians to understand that the time commitment involved far exceeds that of most other course-related instruction. Librarians must also be very flexible in their approaches, as each student and cohort of students will have different research needs and levels of anxieties. While it is often tempting to reuse materials from one course to another, assignments and strategies that may work for one class or cohort may not be as helpful in others. It is important to consider the contexts, needs, and specific anxieties of each department and group of students when developing these relationships and collaborations. Both of us have 
assumed these responsibilities and commitments in addition to, rather than in lieu of, the many other responsibilities we have in our daily jobs.

It is also worth mentioning that both partnerships — with the Theatre department and Architecture department - began with cultivating individual relationships with faculty members. In both cases, the librarian worked to show faculty members that information literacy went beyond finding articles in databases, and that graduate students in particular needed guidance in becoming independent scholars. The process of this can take place in more structured settings such as faculty learning communities, or through the process of writing grants together, or simply through informal conversations. It is also worth noting that while the initial support for embedding a librarian into the graduate research process may have come from an individual faculty member, in both cases, the improved end products of the students led to departmental support. For the Architecture-library partnership, this support is evident in that although there has been turnover in both the faculty member and librarian involved in teaching this course, the partnership has remained, and a librarian continues to work with each cohort of new graduate students. For the Theatre partnership, what began as an information conversation between a faculty member and librarian has grown into a formal part of the curriculum.

\section{Conclusion}

These two case studies demonstrate how librarians can add value to a graduate program and to a graduate student's thesis research process. Although both examples used semester-long embedded approaches that continued informally until the completion of the graduate students' theses, the most important aspect in both was the focus on the affective aspects of the graduate student research experience. By focusing on building personal relationships and fulfilling the 
role of an ally, librarians can help alleviate the anxiety that often hinders graduate students in advancing their thesis research. 


\section{References}

Bartnik, L. (2007). The embedded academic librarian: The subject specialist moves into the discipline college. Kentucky Libraries, 71(3), 4-9.

Barrett, A. (2005). The information-seeking habits of graduate student researchers in the humanities. Journal of Academic Librarianship, 31(4), 324-331.

Blummer, B. (2009). Providing library instruction to graduate students: A review of the literature. Public Services Quarterly, 5(1), 15-39.

Bordonaro, K., \& Richardson, G. (2004). Scaffolding and reflection in course-integrated library instruction. Journal of Academic Librarianship, 30(5), 391-401.

Calkins, K. (2007). Best of the literature: Graduate student instruction. Public Services Quarterly, 3(3/4), 221-226.

Caravello, P. (2007). The literature on academic integrity and graduate students: Issues, solutions, and the case for a librarian role. Public Services Quarterly, 3(3/4), 141-171.

Cummings-Vickaryous, B., Mills, C., Hoeber, L., \& June, L. (2010). Graduate student and instructor engagement in course-based qualitative research: A case study. International Journal for the Scholarship of Teaching \& Learning, 4(2), 1-15.

Green, R., \& Bowser, M. (2002). Managing thesis anxiety: A faculty-librarian partnership to guide off-campus graduate education students through the thesis process. Journal of Library Administration, 37(3/4), 341-354.

Harrington, M. (2009). Information literacy and research-intensive graduate students: Enhancing the role of research librarians. Behavioral \& Social Sciences Librarian, 28(4), 179-201.

Head, A.J., \& Eisenberg, M.B. (2010). Project Information Literacy Progress Report: "Truth be told": How college students evaluate and use information in the digital age. Seattle, 
WA: The Information School, University of Washington. Retrieved from http://projectinfolit.org/pdfs/PIL_Fall2010_Survey_FullReport1.pdf

Jiao, Q.G. \& Onwuegbuzie, A.J. (1997). The antecedents of library anxiety. The Library Quarterly, 67, 372-389.

Kazlauskas, D.W. (1987). Bibliographic instruction at the graduate level: A study of methods (Report No. IR 052931112). East Lansing, MI: National Center for Research on Teacher Learning. (ERIC Document Reproduction Service No. ED 311932).

Kuhlthau, C C. (1988). Developing a model of the library search process: cognitive and affective aspects. $R Q 28$, no. 2:232-242.

Libutti, P, \& Kopala, M. (1995). The doctoral student, the dissertation, and the library: A review of the literature. Reference Librarian, 48, 5-25.

Ongwuebuzie, A.J., Jiao, Q.G, and Bostick, S. (2004). Library anxiety: Theory, research, and applications. Lanham, MD: Scarecrow Press.

Ongwuebuzie, A.J., \& Jiao, Q.G. (1998). Understanding library-anxious graduate students. Library Review, 47(4), 217-224. Retrieved from Library, Information Science \& Technology Abstracts with Full Text database.

Perrett, V. (2004). Graduate information literacy skills: the 2003 ANU skills audit. Australian Library Journal, 53(2), 161-171.

Shumaker, D., \& Talley, M. (2009). Models of embedded librarianship: Final report. Alexandria, VA: Special Libraries Association. Retrieved from http://www.sla.org/pdfs/EmbeddedLibrarianshipFinalRptRev.pdf

Siegel, G. E. (2009). Libraries and graduate students: Building connections. London: Routledge. 